\section{Twenty-four-hour efficacy of the brimonidine/timolol fixed combination versus therapy with the unfixed components}

AGP Konstas', IE Katsimpris², K Kaltsos',

I Georgiadou', A Kordelou², LA Nelson ${ }^{3}$

and WC Stewart ${ }^{4,5}$
${ }^{1}$ Glaucoma Unit, 1st University Department of Ophthalmology, AHEPA Hospital, Thessaloniki, Greece

${ }^{2}$ Department of Ophthalmology, General Hospital 'Agios Andreas', Patras, Greece

The brimonidine/timolol fixed combination (BTFC) (Combigan ${ }^{\mathrm{TM}}$, Allergan Inc., Irvine, CA, USA) is a new fixed combination that has recently been approved in the European Union. Craven et $a l^{1}$ demonstrated that the BTFC, compared to each of its individual components, reduced the morning trough pressure by $28 \%$ from no treatment and $1.6 \mathrm{mmHg}$ from timolol alone. However, the afternoon time point at 1500 hours showed only a $0.6 \mathrm{mmHg}$ further reduction in pressure, whereas at 1700 hours no additional decrease was observed, compared to timolol alone. Further, Sherwood et $a l^{2}$ recently showed, in a meta-analysis of the two

regulatory trials, the BTFC reduced the pressure more than the individual components at all time points except compared to brimonidine at 1700 hours (dosed three times daily). The range of reduction was $4.4-7.6 \mathrm{mmHg}$ with the BTFC, 2.7-5.5 $\mathrm{mmHg}$ with brimonidine, and 3.9-6.2 $\mathrm{mmHg}$ with timolol.

In another comparison, Goni showed that the BTFC provided almost equal efficacy to the unfixed combination of its individual components (brimonidine and timolol dosed twice daily) with reductions ranging from 4.4 to
${ }^{3}$ Charleston Research Company, LLC, Charleston, SC, USA

${ }^{4}$ PRN Pharmaceutical Research Network, LLC, Charleston, SC, USA

${ }^{5}$ Carolina Eye Institute, University of South Carolina, School of Medicine, Columbia, SC, USA

Correspondence:

WC Stewart,

PRN Pharmaceutical Research Network, LLC, 1 Southpark Circle, Suite 110, Charleston, SC 29407, USA

Tel: + 1843762 6500;

Fax: + 18437627444

E-mail: info@prnorb.com

Received: 21 January 2007 Accepted in revised form: 26 April 2007 Published online: 15 June 2007 
$5.3 \mathrm{mmHg}$ in both groups at morning trough and peak time points. ${ }^{3}$ The unfixed combination demonstrated a mean $0.4 \mathrm{mmHg}$ further reduction than the fixed combination measured.

However, as glaucoma is a 24 -h disease, it is important to assess the 24-h efficacy of all new medications ${ }^{4,5}$ and to document the therapeutic equivalency of fixed combinations versus unfixed therapy throughout the 24-h period. Unfortunately, there are no comparative data evaluating the BTFC, compared to the unfixed therapy, beyond the two morning time points evaluated by Goni. ${ }^{3}$

Therefore, the purpose of this study was to evaluate the efficacy of the BTFC versus the unfixed combination of its individual components, each dosed twice daily over the 24-h pressure curve in patients with primary open-angle glaucoma or ocular hypertension.

\section{Materials and methods}

\section{Patients}

The patient population consisted of adults with ocular hypertension or primary open-angle glaucoma. The design was an observer-masked, randomized, crossover, active-controlled comparison. Patients selected for this study were recruited from two clinical sites: Glaucoma Unit, 1st University Department of Ophthalmology, AHEPA Hospital, Thessaloniki, Greece and the Department of Ophthalmology at Agios Andreas Hospital, Patras, Greece. All patients were examined by the two principal investigators (AGPK, IEK).

The protocol of the study was approved by a local IRB, which also approved the informed consent of the trial. The study was in adherence to the tenets of the Declaration of Helsinki. All patients who agreed to participate in the study and met the inclusion and exclusion criteria were enroled.

We included patients of either gender, older than 21 years of age, who demonstrated: willingness to comply with the investigator's and protocol's instructions; a clinical diagnosis of primary open-angle glaucoma or ocular hypertension in at least one eye (study eye); at screening, an intraocular pressure (IOP) considered to be at a level in both eyes, in such a way to assure clinical stability of vision and the optic nerve throughout the trial; at baseline, an untreated IOP of $23-36 \mathrm{mmHg}$ inclusive at the 1000 hours measurement (Visit 2). Patients with glaucoma were defined as those having typical glaucomatous optic atrophy (neural rim thinning, notching, saucerization, or nerve fibre layer disc haemorrhage) with or without typical glaucomatous visual field damage (arcuate, Seidel's or paracentral scotoma or nasal step). Patients with ocular hypertension had no sign of apparent glaucomatous optic disc or visual field damage.

We excluded patients who received therapy if they had a previous history of unresponsiveness (deemed to be an IOP reduction of $<10 \%$ ) to any anti-glaucoma medication, or there was a history of noncompliance. Patients were also excluded from this study if they demonstrated: unreliable applanation tonometry; inadequate visualization of the ocular fundus or anterior chamber; a concurrent infectious/noninfectious conjunctivitis, keratitis, or uveitis; a history of hypersensitivity to any components of the preparations used in this trial; woman of childbearing potential or not using reliable birth control; pregnancy or lactation; a clinically severe medical or psychiatric condition; participation (or current participation) in any investigational drug or device trial within the previous 30 days before the screening visit; an intraocular conventional surgery or laser surgery; risk of visual field or visual acuity worsening as a consequence of participation in the trial, a cup to disc ratio of 0.8 or worse or a mean deviation of worse than $-14 \mathrm{~dB}$ on visual field testing (not attributable to cataract); an inability to give informed consent; anticipated change in systemic hypotensive therapy during the active treatment portion of the trial (Visits 2-6); progressive retinal or optic nerve disease apart from glaucoma; reactive airway disease, second or third degree heart block, poorly compensated congestive heart failure or concomitant use of systemic beta-blockers.

\section{Procedures}

The methods for this study were similar to those described previously. ${ }^{6-12}$ All patients signed an Institutional Review Board approved informed consent form before enrollment. Previously treated patients underwent an untreated washout period comprising 4 weeks for brimonidine, or dorzolamide; 5 weeks for beta-blockers or the dorzolamide/timolol fixed combination; and 6 weeks for prostaglandin analogues. ${ }^{13}$

At Visit 2, patients who qualified by the IOP criteria for the study underwent a 24-h monitoring of their untreated sitting IOP with measurements at 0600, 1000, 1400, 1800, 2200, and 0200 hours. Patients then were randomly assigned by a dosing coordinator, using a computer generated randomized numbers list, to receive either the BTFC or brimonidine and timolol (given separately 15 min apart) for the first 3-month treatment period. Patients were asked to instill the study medicine at 0800 and 2000 hours. Patients were then crossed over to the second treatment period for another 3-month period. During the last 24-h of each treatment period, patients underwent 24-h IOP measurements like those at Visit 2. 
The 3-month treatment period was chosen to avoid a carryover effect of the medications under investigation. ${ }^{13}$ No washout period was included between treatment periods.

During the assessment of the sitting 24-h pressure curve, the investigator who performed the IOP measurements was masked to the treatment regimen and the same investigators used the same calibrated instruments (Goldmann applanation tonometer) to perform 24-h IOP curves. The medication was donated from Alvia Inc., Athens, Greece. Patients were admitted to the hospital in the morning for 24 -h pressure testing. At the 2200 hours measurement, patients were awake at bed rest. The 0200 and 0600 hours IOP measurements were performed $5-10 \mathrm{~min}$ immediately after wakening and at the slit lamp. Patients were encouraged to carry out a normal life as much as possible within the hospital boundaries.

Masking was performed by placing a label with the patient number over the study medicine bottle that was purchased from the manufacturer. The patients were instructed not to show the medicine bottle to any study personnel or physician (except a designated dosing coordinator).

Regarding correct medication instillation and adherence, patients were instructed to wait $15 \mathrm{~min}$ between drops. In this study, all patients were instructed to perform nasolacrimal occlusion for $1 \mathrm{~min}$ after instillation of each study eye drop. At each visit, adverse events were recorded based upon the patient's unsolicited complaints or following a general query such as 'How are you doing?'

\section{Statistics}

Statistical analyses comparing the primary efficacy variable, 24-h IOP (average IOP for the six time points evaluated), were performed using a repeated measures of analysis. Individual time points were evaluated with a paired $t$-test within the analysis of variance. ${ }^{14-17}$ The significance level was set at 0.05 and a two-way, analysis was used for all tests. This study had an $80 \%$ power to identify a $1.5 \mathrm{mmHg}$ difference between individual time points and between mean 24-h IOPs, assuming a standard deviation of $2.8 \mathrm{mmHg}$ between treatments. ${ }^{6,18-20}$ The difference of $1.5 \mathrm{mmHg}$ was chosen to be consistent with regulatory agency requirements of the clinical evaluation of new glaucoma medications. In a patient with bilateral glaucoma, one eye was randomly chosen at the time of enrollment for analysis. The number of patients who suffered individual adverse events between treatment groups was evaluated by a McNemar test. ${ }^{21}$

\section{Results \\ Patients}

There were 32 patients enroled in this study and 28 patients completed at least one time point at each 24-h curve visit for both medications. There were four patients who did not complete the trial due to side effects while on the fixed combination (one patient discontinued due to ocular intolerance), or the unfixed therapy (three patients discontinued; one due to systemic hypotension and two due to ocular intolerance). Patients who completed the study are described in Table 1.

\section{Intraocular pressure}

The absolute values for the IOPs are found in Table 2 and in the Figure 1. Both the fixed and unfixed combinations showed a statistical reduction from baseline for each time point and for the 24 -h curve $(P<0.0001)$. When treatment

Table 1 Baseline characteristics

\begin{tabular}{llc}
\hline Parameter & Detail & All patients \\
\hline Age & Years & $63.6 \pm 8.6$ \\
Gender & Female & 10 \\
& Male & 18 \\
Pachymetry & & $549.6 \pm 26.3$ \\
Visual acuity & & $0.8 \pm 0.2$ \\
Cup/disc ratio & & $0.5 \pm 0.1$ \\
Mean defect & & $5.0 \pm 2.9$ \\
Previous therapy & Dorzolamide/timolol fixed & 8 \\
& combination & \\
& No therapy & 4 \\
& Timolol & 4 \\
& Timolol and latanoprost & 2 \\
& Timolol and travoprost & 1 \\
& Dorzolamide/timolol fixed & \\
& combination and latanoprost & 1 \\
& Bimatoprost & 1 \\
& Timolol and brinzolamide & 1 \\
& Latanoprost/timolol fixed & \\
& combination & \\
& Brinzolamide &
\end{tabular}

Table 2 Mean intraocular pressures $(\mathrm{mmHg} \pm \mathrm{SD})$

\begin{tabular}{lccccc}
\hline Time points & $\mathrm{n}$ & Baseline & Fixed & Unfixed & P-value \\
\hline 0600 & 28 & $24.6 \pm 3.2$ & $19.2 \pm 2.5$ & $19.1 \pm 2.4$ & 0.8 \\
1000 & 28 & $26.9 \pm 2.8$ & $20.0 \pm 2.1$ & $19.8 \pm 1.8$ & 0.7 \\
1400 & 28 & $25.1 \pm 1.9$ & $19.7 \pm 2.1$ & $20.1 \pm 1.6$ & 0.4 \\
1800 & 28 & $24.4 \pm 1.9$ & $19.7 \pm 2.3$ & $20.0 \pm 2.0$ & 0.6 \\
2200 & 28 & $23.6 \pm 1.8$ & $18.3 \pm 1.9$ & $18.0 \pm 1.6$ & 0.5 \\
0200 & 28 & $22.9 \pm 2.0$ & $18.4 \pm 2.3$ & $18.2 \pm 2.4$ & 0.7 \\
24-hour & 28 & $24.6 \pm 1.9$ & $19.2 \pm 1.9$ & $19.2 \pm 1.6$ & 1.0 \\
\hline
\end{tabular}




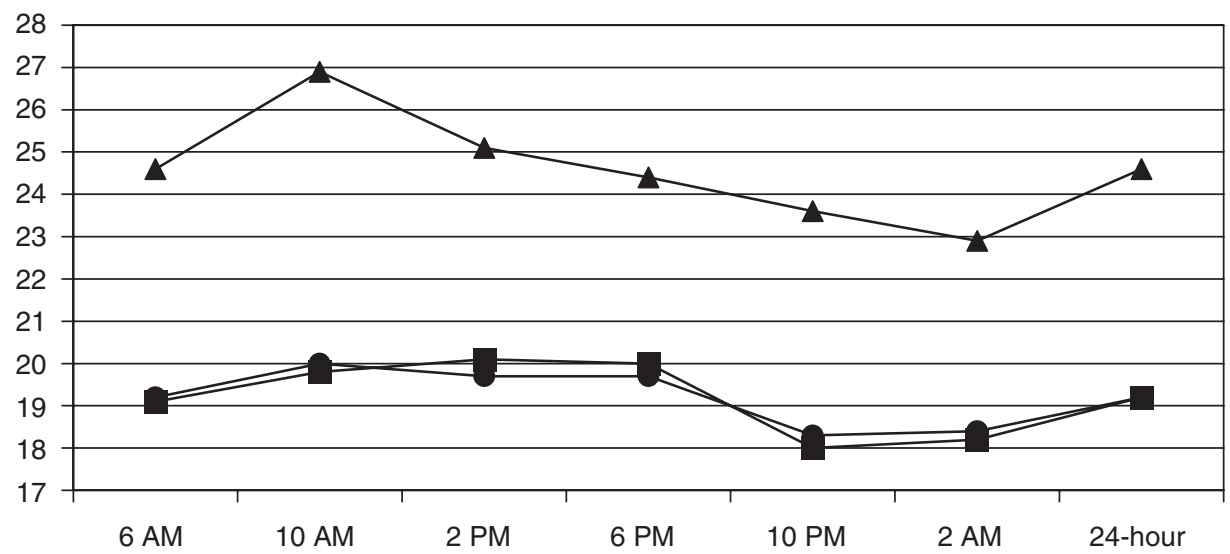

Figure 1 The comparison of IOP at untreated baseline (triangles) versus the BTFC (circles) and the unfixed components (squares) for the 24-h curve.

groups were compared directly, there was no statistical difference in the absolute level of IOP for the 24-h curve or for any individual time point $(P>0.4)$.

The IOP reductions for each time point, and for the 24-h curve, are found in Table 3 . The results between treatment groups are similar to the absolute levels of pressure mentioned above for the 24-h curve and individual time points $(P>0.5)$.

\section{Adverse events}

There were eight ocular adverse events documented with the fixed combination and 12 with the unfixed components. The most common ocular adverse event was hyperaemia ( $n=3$ with the fixed combination and $n=5$ with the unfixed therapy, $P=0.7$; Table 4 ).

There were two systemic adverse events with the fixed combination and three with the unfixed components: headache ( $n=2$ with the fixed combination and $n=2$ with the unfixed components) and dry mouth ( $n=1$ with the unfixed combination, $P=1.0$ ).

\section{Discussion}

Several prior studies have evaluated commercially available fixed combinations to their unfixed components. Generally, these studies have shown that the unfixed combination usually provides a marginally greater, but not statistically significant, reduction in IOP compared to the fixed combination containing the same medicines.

Specifically, Strohmaier et $a l^{22}$ found that the dorzolamide/timolol fixed combination $\left(\mathrm{Cosopt}^{\mathrm{TM}}\right.$, Merck \& Co., Whitehouse Station, NJ, USA) was $0.7 \mathrm{mmHg}$ than its individual components (dorzolamide dosed three times daily). Diestelhorst and Larsson ${ }^{23}$ showed that the latanoprost/timolol fixed combination
Table 3 Intraocular pressure reductions from baseline $(\mathrm{mmHg} \pm \mathrm{SD})$

\begin{tabular}{lcccc}
\hline Time points & $\mathrm{n}$ & Fixed & Unfixed & P-value \\
\hline 0600 & 28 & $5.4 \pm 1.7$ & $5.5 \pm 2.3$ & 0.8 \\
1000 & 28 & $6.9 \pm 2.3$ & $7.1 \pm 2.8$ & 0.8 \\
1400 & 28 & $5.4 \pm 2.3$ & $5.0 \pm 2.0$ & 0.5 \\
1800 & 28 & $4.6 \pm 1.9$ & $4.3 \pm 2.3$ & 0.6 \\
2200 & 28 & $5.3 \pm 1.4$ & $5.6 \pm 1.5$ & 0.5 \\
0200 & 28 & $4.5 \pm 1.9$ & $4.7 \pm 2.2$ & 0.7 \\
24 -hour & 28 & $5.3 \pm 1.2$ & $5.4 \pm 1.6$ & 1.0 \\
\hline
\end{tabular}

Table 4 Most common ocular adverse events ( $n=2$ or greater)

\begin{tabular}{lccc}
\hline Ocular adverse events & Fixed & Unfixed & P-value \\
\hline Hyperaemia & 3 & 5 & 0.7 \\
Superficial punctate keratitis & 2 & 2 & 1.0 \\
Itchiness & 1 & 2 & 1.0 \\
Watering & 1 & 2 & 1.0 \\
Stinging & 1 & 1 & 1.0 \\
\hline
\end{tabular}

(Xalacom $^{\mathrm{TM}}$, Pfizer Inc., New York, NY, USA), dosed in the morning, was $1.1 \mathrm{mmHg}$ less effective than its unfixed combination (latanoprost dosed in the evening, timolol dosed twice daily). However, a repeat study by Diestelhorst and Larsson, ${ }^{24}$ with evening dosing of latanoprost, found the fixed combination only $0.3 \mathrm{mmHg}$ less effective than the unfixed combination. In addition, several articles have evaluated morning-dosed travoprost/timolol fixed combination with its unfixed components (travoprost dosed in the evening and timolol once daily). Schuman et al, as well as Hughes et al, demonstrated the mean IOPs were 0.8 and $0.7 \mathrm{mmHg}$ greater with morning-dosed travoprost/timolol fixed combination (Duotrav $^{\mathrm{TM}}$, Alcon, Inc., Forth Worth, TX, USA), respectively, compared with unfixed therapy. ${ }^{25,26}$ 
The purpose of the present study was to evaluate the efficacy of the BTFC versus the unfixed combination of its individual components, each dosed twice daily over the 24-h pressure curve in patients with primary open-angle glaucoma or ocular hypertension.

This study showed that both the fixed and unfixed combinations statistically reduced the IOP from untreated baseline, at each individual time point, and for the 24-h pressure curve. When both treatments were compared directly, they demonstrated a statistically equal IOP level at each individual time point and for the 24-h pressure curve. Our results are similar to the parallel study by $\mathrm{Goni}^{3}$ for the morning trough and peak time points, but extend the knowledge of the pressure curve between these two treatment regimens for the complete 24-h day.

Nonetheless, the results of the current crossover study differ from previous studies comparing other fixed combinations to their unfixed individual components in that the IOPs in our study were the same, or very close, between treatments. Importantly, the design of the present 24-h study differed from previous diurnal trials examining a fixed combination versus concomitant unfixed therapy, in that, both treatment regimes were compared with the same dosing frequency and schedule. ${ }^{3}$ In previous trials, with the exception of Goni and co-workers, there were differences in the frequency of dosing between the fixed and unfixed therapy combinations (eg, timolol once versus twice daily or dorzolamide twice versus three times daily) or with the dosing schedule (eg, the prostaglandin dosed in the evening versus morning). ${ }^{23,24,27,28}$ These design differences in the dosing may have accounted for the small differences in pressures between the fixed and unfixed combinations in previous studies.

The extent of pressure reduction over 24 -h in our study with the brimonidine/timolol fixed and unfixed combination, from untreated baseline, was on average $22 \%$ with a 24 -h range of $19-26 \%$ (daytime range also $19-26 \%$ ). This range of pressure reduction mirrors the regulatory trials for the BTFC. ${ }^{1,2}$ However, the extent of IOP reduction from untreated baseline is less than observed with other fixed combination therapies, which have ranged in the daytime from 27 to $29 \%$ with the dorzolamide/timolol fixed combination ${ }^{27,29,30}$ and $30-38 \%$ with the prostaglandin analogue/timolol fixed combinations. ${ }^{28,31-33}$

The reason for the reduced efficacy difference with the BTFC in our study is not known precisely, but may have resulted from the decreased pressure response in the afternoon compared with other fixed combinations. This finding was consistent with the regulatory trials, when there was little difference between the BTFC and its individual components (brimonidine dosed three times daily) at 1700 hours. ${ }^{1,3}$ However, the reduced efficacy in the afternoon in the current trial may also be due to the lower baseline pressures during this time period. Further, the efficacy of the individual components alone was not compared with the fixed combination or unfixed components in our trial. Consequently, the continued efficacy of both components of the fixed combination throughout the complete dosing cycle could not be confirmed or denied based on our data.

Importantly, the value of the fixed combination compared with the individual components cannot be measured completely by ocular hypotensive efficacy. The fixed combinations have several advantages over the unfixed components. First, they eliminate the need to separate dosing as shown by Chrai et al, ${ }^{34}$ who indicated at least $5 \mathrm{~min}$ was required before instilling a second treatment to avoid washing out the first. Second, the fixed combination simplifies therapy and should help compliance. Several studies have indicated that compliance is improved by reducing dosing to twice daily and decreasing the number of bottles. ${ }^{35-37}$ Further, Stewart et $a l^{38}$ have shown that European patients and physicians like the concept of once daily dosing. However, no direct proof yet exists that a fixed combination aids compliance.

The ocular adverse events found in this study were statistically similar between treatments with the most common being ocular hyperaemia in $11 \%$ of patients in the fixed combination group and $18 \%$ of patients in the unfixed group. Systemic adverse events were unusual in both groups.

This study suggests that both the BTFC and the unfixed components of brimonidine and timolol, when dosed twice daily, provide a statistical reduction from untreated baseline and statistically equal pressures when compared directly, at each time point and for the 24-h pressure curve.

This study did not evaluate the long-term 24-h efficacy of the fixed combination versus its individual components or unfixed therapy. This study also did not compare the BTFC to other fixed combinations. More research is needed to further clarify the best-fixed combination therapy and the stepwise order of therapy to treat ocular hypertension and primary open-angle glaucoma.

\section{Acknowledgements}

This clinical trial did not receive direct financial support from any public or private funding organization. The medication was donated from Alvia Inc., Athens, Greece. None of the authors had any proprietary interest in the products mentioned in this study. 


\section{References}

1 Craven ER, Walters TR, Williams R, Chou C, Cheetham JK, Schiffman $\mathrm{R}$ et al. Brimonidine and timolol fixedcombination therapy versus monotherapy: a 3-month randomized trial in patients with glaucoma or ocular hypertension. J Ocul Pharmacol Ther 2005; 21: 337-348.

2 Sherwood MB, Craven ER, Chou C, DuBiner HB, Batoosingh AL, Schiffman RM et al. Twice-daily $0.2 \%$ brimonidine- $0.5 \%$ timolol fixed-combination therapy vs monotherapy with timolol or brimonidine in patients with glaucoma or ocular hypertension: a 12-month randomized trial. Arch Ophthalmol 2006; 124: 1230-1238.

3 Goni FJ, Brimonidine/Timolol Fixed Combination Study Group. 12-week study comparing the fixed combination of brimonidine and timolol with concomitant use of the individual components in patients with glaucoma and ocular hypertension. Eur J Ophthalmol 2005; 15: 581-590.

4 Asrani S, Zeimer R, Wilensky J, Gieser D, Vitale S, Lindenmuth K. Large diurnal fluctuations in intraocular pressure are an independent risk factor in patients with glaucoma. J Glaucoma 2000; 9: 134-142.

5 Konstas AG, Hollo G, Astakhov YS, Teus MA, Akopov EL, Jenkins JN et al. Factors associated with long-term progression or stability in exfoliation glaucoma. Arch Ophthalmol 2004; 122: 29-33.

6 Konstas AG, Nakos E, Tersis I, Lallos NA, Leech JN, Stewart WC. A comparison of once-daily morning vs evening dosing of concomitant latanoprost/timolol. Am J Ophthalmol 2002; 133: 753-757.

7 Konstas AG, Papapanos P, Tersis I, Houliara D, Stewart WC. Twenty-four-hour diurnal curve comparison of commercially available latanoprost $0.005 \%$ versus the timolol and dorzolamide fixed combination. Ophthalmology 2003; 110: 1357-1360.

8 Konstas AG, Kozobolis VP, Tersis I, Leech J, Stewart WC. The efficacy and safety of the timolol/dorzolamide fixed combination vs latanoprost in exfoliation glaucoma. Eye 2003; 17: 41-46.

9 Konstas AG, Stewart WC, Topouzis F, Tersis I, Holmes KT, Stangos NT. Brimonidine $0.2 \%$ given two or three times daily versus timolol maleate $0.5 \%$ in primary open-angle glaucoma. Am J Ophthalmol 2001; 131: 729-733.

10 Konstas AG, Lake S, Maltezos AC, Holmes KT, Stewart WC. 24 hour intraocular pressure reduction with latanoprost compared with pilocarpine as third-line therapy in exfoliation glaucoma. Eye 2001; 15: 59-62.

11 Konstas AG, Maltezos A, Bufidis T, Hudgins AG, Stewart WC. Twenty-four hour control of intraocular pressure with dorzolamide and timolol maleate in exfoliation and primary open-angle glaucoma. Eye 2000; 14: 73-77.

12 Konstas AG, Katsimbris JM, Lallos N, Boukaras GP, Jenkins JN, Stewart WC. Latanoprost $0.005 \%$ versus bimatoprost $0.03 \%$ in primary open-angle glaucoma patients. Ophthalmology 2005; 112: 262-266.

13 Stewart WC, Holmes KT, Johnson MA. Washout periods for brimonidine $0.2 \%$ and latanoprost $0.005 \%$. Am J Ophthalmol 2001; 131: 798-799.

14 Orzalesi N, Rossetti L, Bottoli A, Fumagalli E, Fogagnolo P. Effect of latanoprost, brimonidine, and a fixed combination of timolol and dorzolamide on circadian intraocular pressure in patients with glaucoma or ocular hypertension. Arch Ophthalmol 2003; 121: 453-457.
15 Konstas AG, Mantziris DA, Stewart WC. Diurnal intraocular pressure in untreated exfoliation and primary open-angle glaucoma. Arch Ophthalmol 1997; 115: 182-185.

16 Konstas AG, Mantziris DA, Cate EA, Stewart WC. Effect of timolol on the diurnal intraocular pressure in exfoliation and primary open-angle glaucoma. Arch Ophthalmol 1997; 115: 975-979.

17 Book SA. Essentials of Statistics. McGraw-Hill: New York, 1978; 117-122.

18 Mundorf TK, Cate EA, Sine CS, Otero DW, Stewart JA, Stewart WC. Safety and efficacy of switching timolol maleate $0.5 \%$ solution to timolol hemihydrate $0.5 \%$ solution given twice daily. J Ocul Pharmacol Ther 1998; 14: 129-135.

19 Duff GR. A double-masked crossover study comparing the effects of carteolol 1\% and 2\% on intra-ocular pressure. Acta Ophthalmol (Copenh) 1987; 65: 618-621.

20 Stewart WC, Day DG, Stewart JA, Schuhr J, Latham KE. The efficacy and safety of latanoprost $0.005 \%$ once daily versus brimonidine $0.2 \%$ twice daily in open-angle glaucoma or ocular hypertension. Am J Ophthalmol 2001; 131: 631-635.

21 Siegel S. Nonparametric Statistics for the Behavioral Sciences. McGraw Hill: New York, 1956; 63-67.

22 Strohmaier K, Snyder E, DuBiner H, Adamsons I. The efficacy and safety of the dorzolamide-timolol combination versus the concomitant administration of its components. Dorzolamide-Timolol Study Group. Ophthalmology 1998; 105: 1936-1944

23 Diestelhorst M, Larsson LI, European Latanoprost Fixed Combination Study Group. A 12 week study comparing the fixed combination of latanoprost and timolol with the concomitant use of the individual components in patients with open angle glaucoma and ocular hypertension. $\mathrm{Br} \mathrm{J}$ Ophthalmol 2004; 88: 199-203.

24 Diestelhorst M, Larsson LI, European-Canadian Latanoprost Fixed Combination Study Group. A 12-week, randomized, double-masked, multicenter study of the fixed combination of latanoprost and timolol in the evening versus the individual components. Ophthalmology 2006; 113: 70-76.

25 Schuman JS, Katz GJ, Lewis RA, Henry JC, Mallick S, Wells DT et al. Efficacy and safety of a fixed combination of travoprost $0.004 \%$ /timolol $0.5 \%$ ophthalmic solution once daily for open-angle glaucoma or ocular hypertension. Am J Ophthalmol 2005; 140: 242-250.

26 Hughes BA, Bacharach J, Craven ER, Kaback MB, Mallick S, Landry TA et al. A three-month, multicenter, doublemasked study of the safety and efficacy of travoprost $0.004 \%$ /timolol $0.5 \%$ ophthalmic solution compared to travoprost $0.004 \%$ ophthalmic solution and timolol $0.5 \%$ dosed concomitantly in subjects with open angle glaucoma or ocular hypertension. J Glaucoma 2005; 14: 392-399.

27 Boyle JE, Ghosh K, Gieser DK, Adamsons IA. A randomized trial comparing the dorzolamide-timolol combination given twice daily to monotherapy with timolol or dorzolamide. Ophthalmology 1999; 106: 10-16.

28 Fechtner RD, Airaksinen PJ, Getson AJ, Lines CR, Adamsons IA, COSOPT versus XALATAN Study Groups. Efficacy and tolerability of the dorzolamide 2\%/timolol $0.5 \%$ combination (Cosopt) versus $0.005 \%$ (Xalatan) in the treatment of ocular hypertension or glaucoma: results from two randomized clinical trials. Acta Ophthalmol Scand 2004; 82: $42-48$

29 Shin DH, Feldman RM, Sheu WP, Fixed Combination Latanoprost/Timolol Study Group. Efficacy and safety of 
the fixed combinations latanoprost/timolol versus dorzolamide/timolol in patients with elevated intraocular pressure. Ophthalmology 2004; 111: 276-282.

30 Pfeiffer N, German Latanoprost Fixed Combination Study Group. A comparison of the fixed combination of latanoprost and timolol with its individual components. Graefes Arch Clin Exp Ophthalmol 2002; 240: 893-899.

31 Higginbotham EJ, Feldman R, Stiles M, Dubiner H. Latanoprost and timolol combination therapy vs monotherapy: one-year randomized trial. Arch Ophthalmol 2002; 120: 915-922.

32 Barnebey HS, Orengo-Nania S, Flowers BE, Samples J, Mallick S, Landry TA et al. The safety and efficacy of travoprost $0.004 \% /$ timolol $0.5 \%$ fixed combination ophthalmic solution. Am J Ophthalmol 2005; 140: 1-7.

33 Denis P, Andrew R, Wells D, Friren B. A comparison of morning and evening instillation of a combination travoprost $0.004 \%$ /timolol $0.5 \%$ ophthalmic solution. Eur J Ophthalmol 2006; 16: 407-415.

34 Chrai SS, Makoid MC, Eriksen SP, Robinson JR. Drop size and initial dosing frequency problems of topically applied ophthalmic drugs. J Pharm Sci 1974; 63: 333-338.

35 Kass MA, Meltzer DW, Gordon M, Cooper D, Goldberg J. Compliance with topical pilocarpine treatment. Am J Ophthalmol 1986; 101: 515-523.

36 Granström PA. Glaucoma patients not compliant with their drug therapy: clinical and behavioral aspects. $\mathrm{Br} J$ Ophthalmol 1982; 66: 464-470.

37 Bloch S, Rosenthal AR, Friedman L, Caldarolla P. Patient compliance in glaucoma. Br J Ophthalmol 1977; 61: 531-534.

38 Stewart WC, Konstas AG, Pfeiffer N. Patient and ophthalmologist attitudes concerning compliance and dosing in glaucoma treatment. J Ocul Pharmacol Ther 2004; 20: 461-469. 